\title{
Musculoskeletal imaging
}

\section{Presentation}

A 33-year-old female runner presented with chronic right hip pain. These are selected plain film, computed tomography (CT) and magnetic resonance (MR) images.

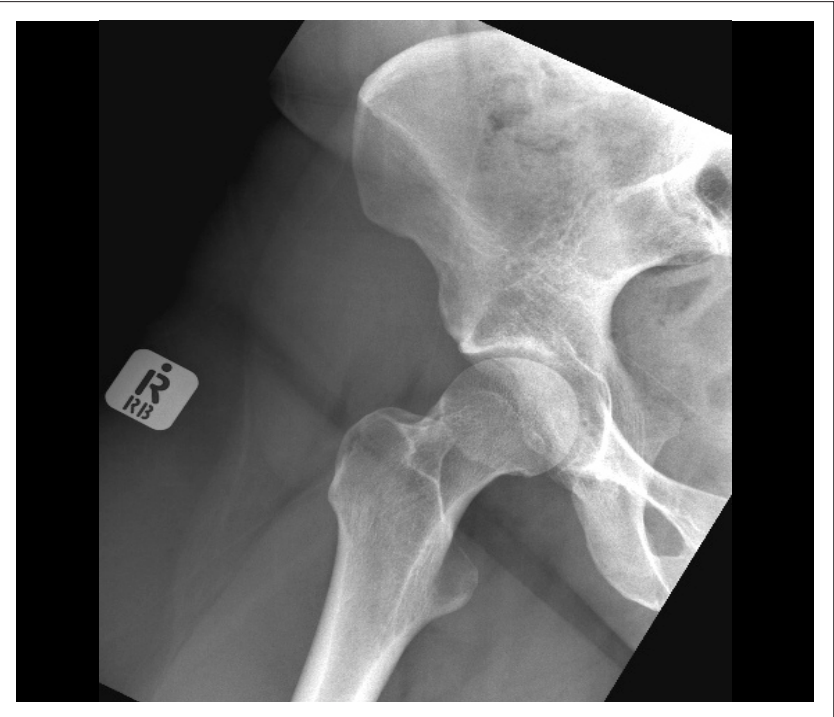

FIGURE 1: Plain radiograph of right hip.

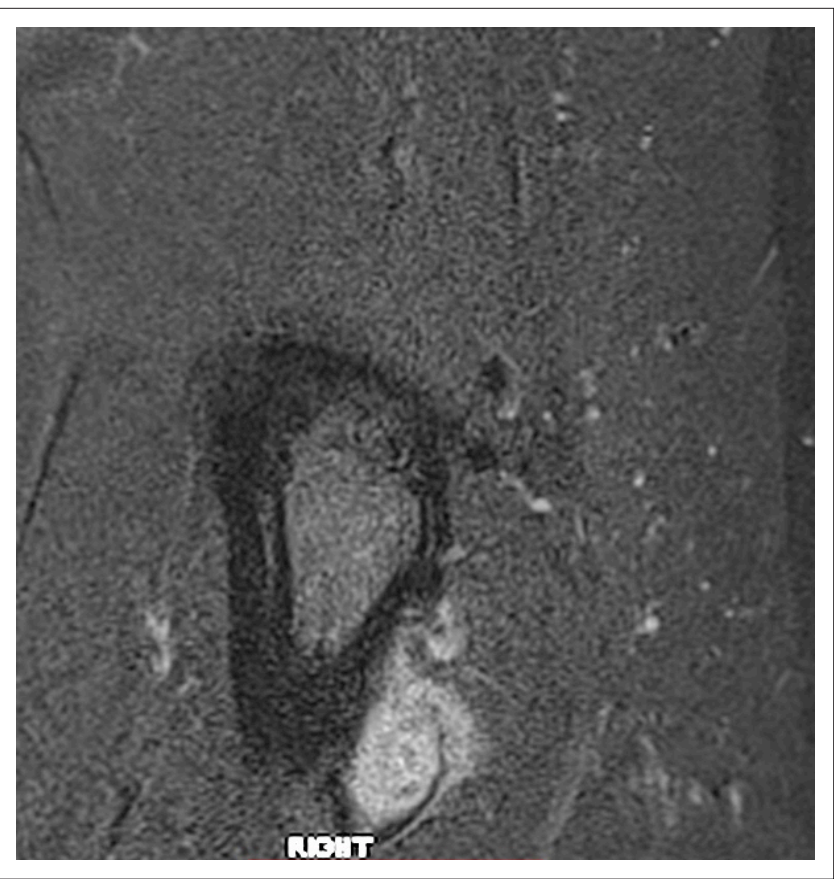

FIGURE 3: Sagittal proton-density magnetic resonance (MR) image of right hip.

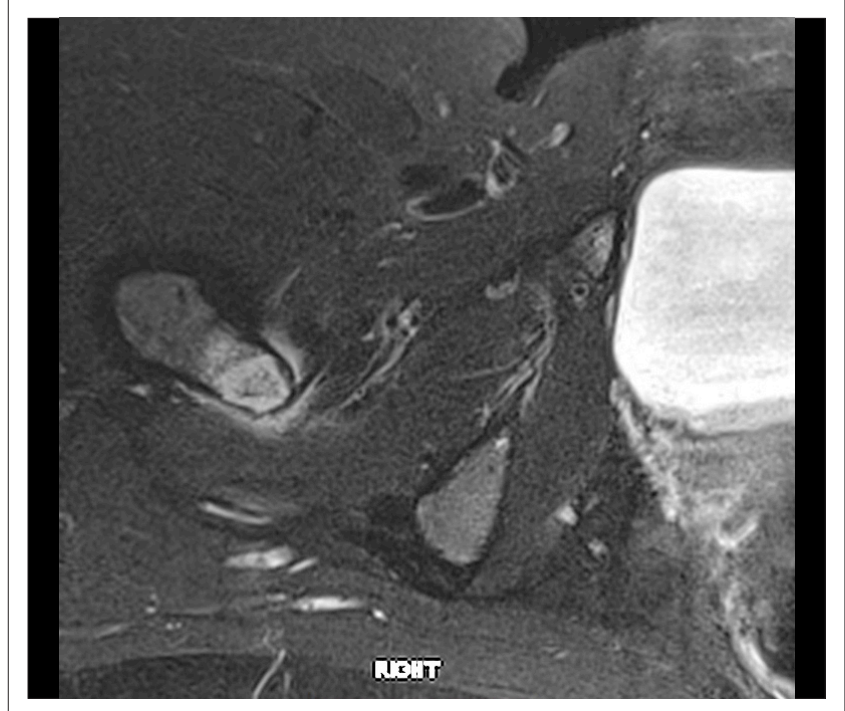

FIGURE 2: Axial T2-weighted magnetic resonance (MR) image of right hip.

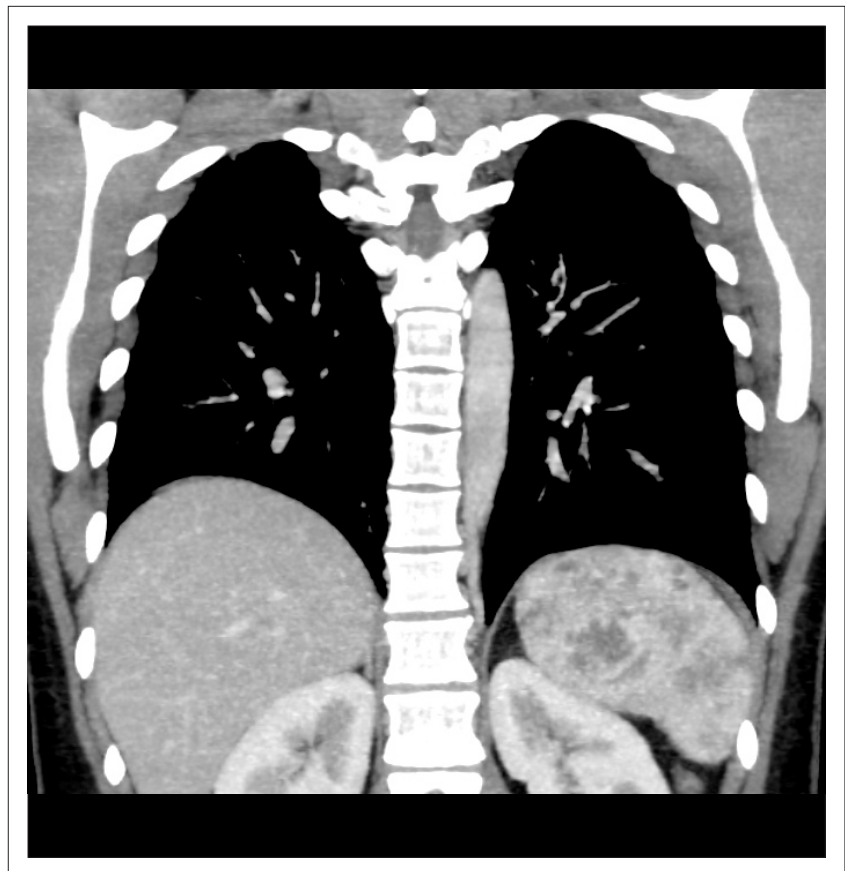

FIGURE 4: Coronal computed tomography (CT) reformat of chest and abdomen.
Read online:

口:125:

74:- code with your

(1)

口ift to read online
Authors: Shalendra K. Misser ${ }^{1}$; J.M. Zietkiewicz

Affiliations: ${ }^{1}$ Lake Smit and Partners Inc, Durban, South Africa

Correspondence to: Shalendra Misse

Email: misser@lakesmit.co.za

Postal address: Private Bag X08, Overport 4067, Durban, KwaZulu-Natal, South Africa

How to cite this article: Misser SK, Zietkiewicz JM. Musculoskeletal imaging. S Afr J Rad. 2014;18(1); Art. \#702, 2 pages. http://dx.doi. org/10.4102/sajr.v18i1.702

Copyright: (C) 2014. The Authors. Licensee: AOSIS OpenJournals. This work is licensed under the Creative Commons Attribution License. 


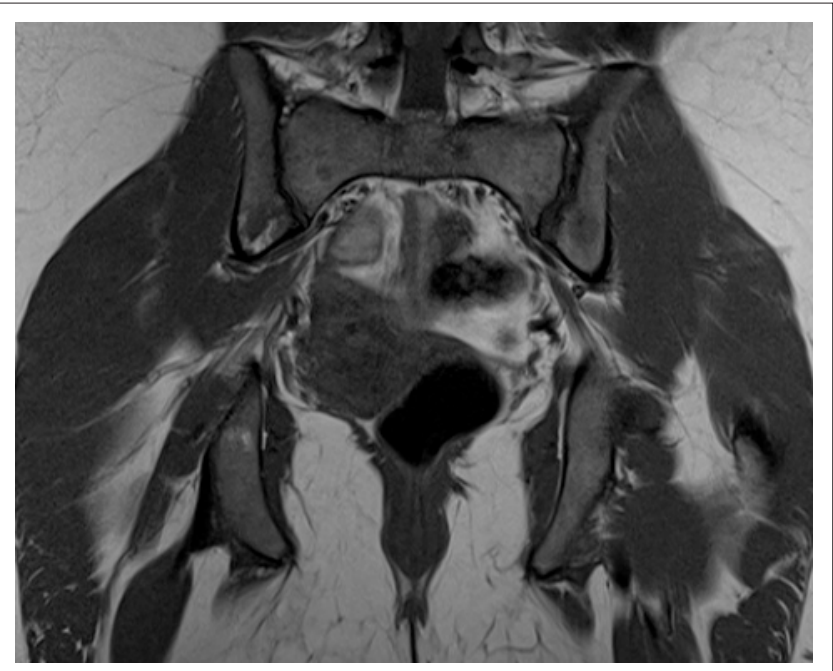

FIGURE 5a: Coronal T1-weighted magnetic resonance (MR) image of pelvis.

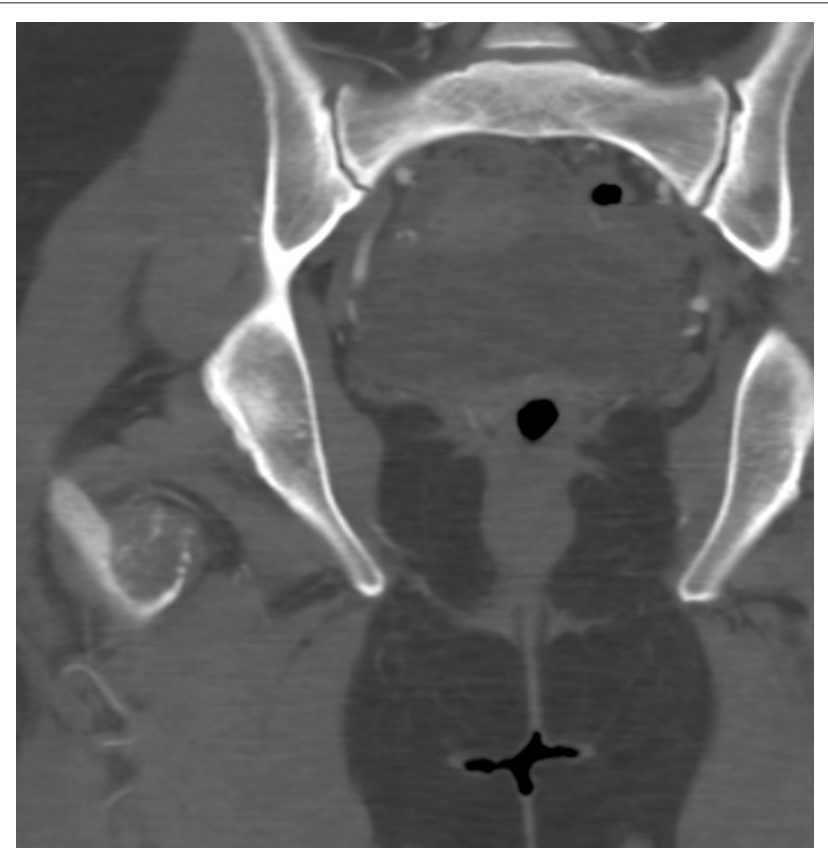

FIGURE 6a: Coronal computed tomography (CT) reformat image of right hip.

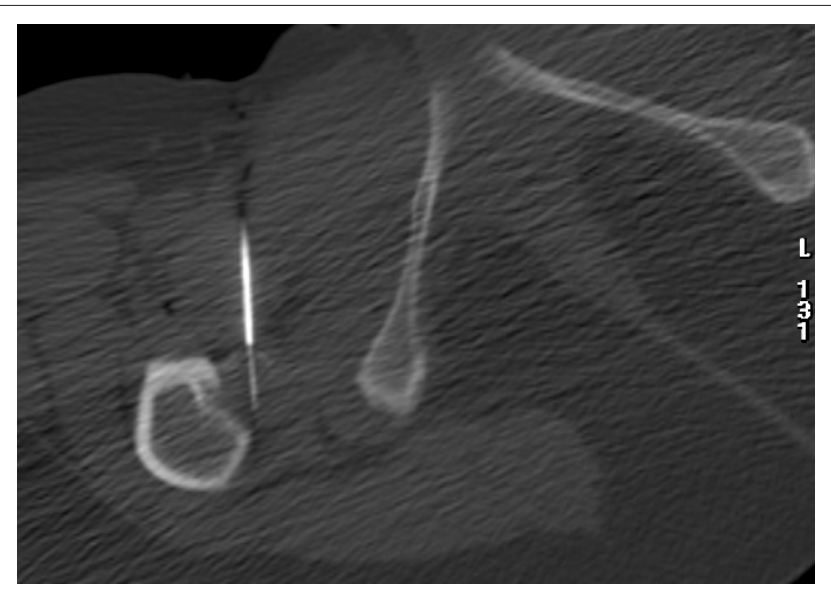

FIGURE 7: Axial computed tomography (CT) image acquired in biopsy mode.

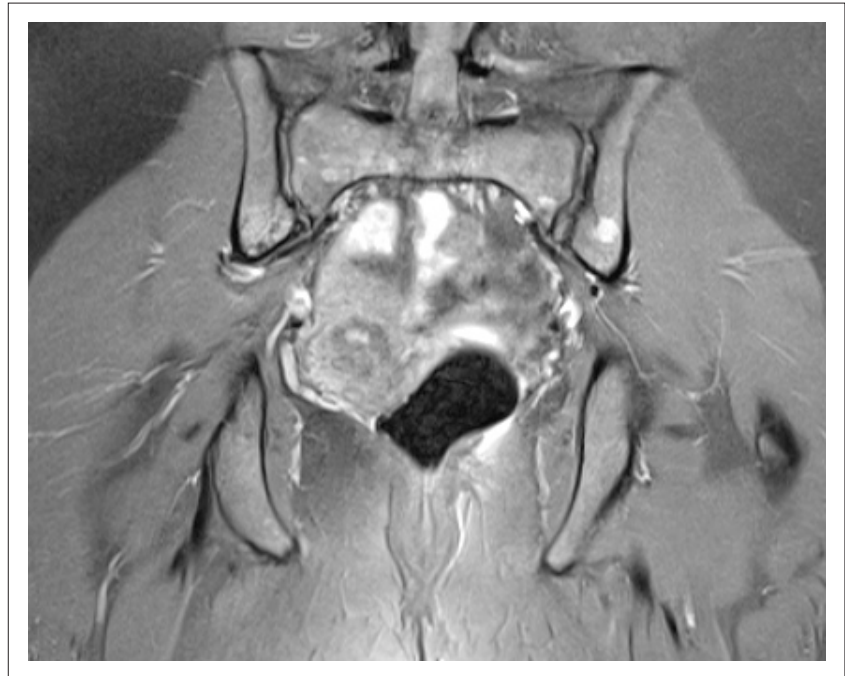

FIGURE 5b: Coronal proton density magnetic resonance (MR) image of pelvis.

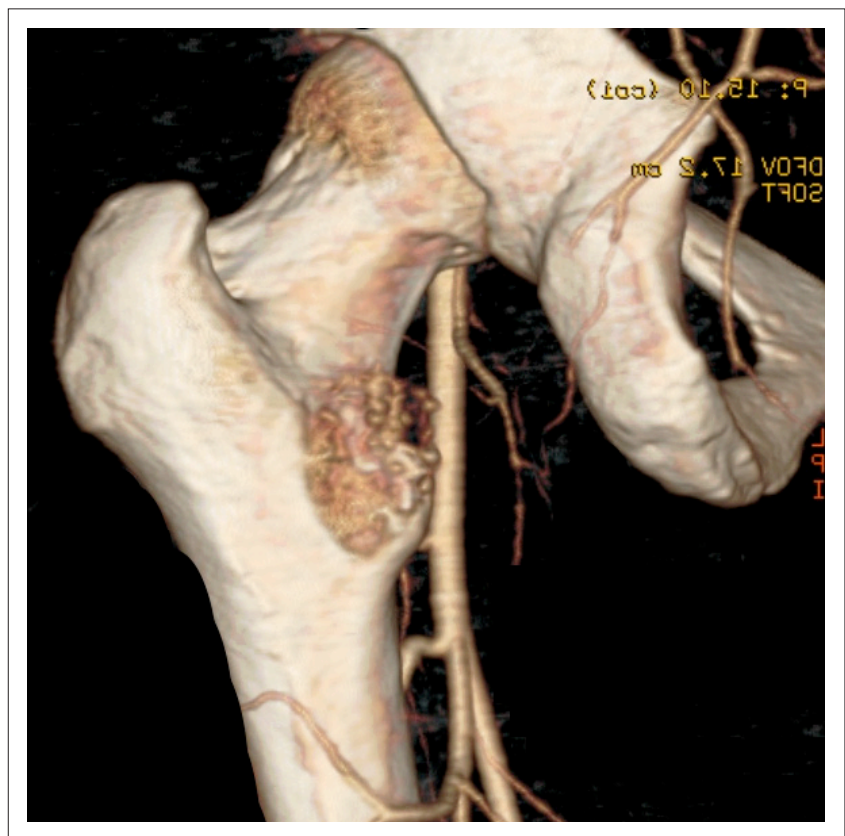

FIGURE 6b: Volume rendered computed tomography angiography (CTA) reformat of right hip.

Describe the relevant findings and provide the most appropriate clinical diagnosis. Please submit your response to Dr Misser at misser@lakesmit.co.za not later than 01 December 2014. The winning respondent will receive a R1000 award from the RSSA. A detailed diagnosis and discussion will be presented later this year. 